\title{
Percepções de gestores locais sobre a intersetorialidade no Programa Saúde na Escola*
}

\author{
IZABEL DO ROCIO COSTA FERREIRA \\ Universidade Federal do Paraná, \\ Curitiba, PR, Brasil
}

SAMUEL JORGE MOYSÉS

Pontifícia Universidade Católica do

Paraná, Curitiba, PR, Brasil

BEATRIZ HELENA SOTTILE FRANÇA

Pontifícia Universidade Católica do

Paraná, Curitiba, PR, Brasil

MAX LUIZ DE CARVALHO Pontifícia Universidade Católica do

Paraná, Curitiba, PR, Brasil

SIMONE TETU MOYSÉS

Pontifícia Universidade Católica do

Paraná, Curitiba, PR, Brasil

\section{INTRODUÇÃO}

O decreto presidencial n. 6.286, de 5 de dezembro de 2007 (Brasil, 2007), instituiu o Programa Saúde na Escola (PSE), que dá concretude a uma política intersetorial entre os Ministério da Saúde (MS) e o Ministério da Educação (MEC), abrangendo os entes federados nos três níveis de governo (federal, estadual e municipal).

* Agradecemos à Coordenação de Aperfeiçoamento de Pessoal de Nível Superior (CAPES), que concedeu bolsa de doutorado para a autora Izabel do Rocio Costa Ferreira. 
Essa política tem como concepção a oferta de ações de atenção integral (prevenção, promoção e atenção) à saúde de estudantes da educação básica pública brasileira, que compreende a educação infantil, o ensino fundamental e médio, a educação profissional e tecnológica e a educação de jovens e adultos (EJA), no espaço das escolas e/ou Unidades Básicas de Saúde (UBS) do Sistema Único de Saúde (SUS) (Brasil, 2008a).

As ações de saúde na escola são realizadas pelas Equipes de Saúde da Família (ESFs), indispensáveis para a efetivação do programa (Brasil, 2007, 2008a), o que é destacado por Mendonça (2008) ao observar que a singularidade do PSE é ter sido implementado segundo o modelo brasileiro de atenção primária à saúde. As ações do PSE são produzidas em territórios determinados, de acordo com a área de abrangência das ESFs, estimulando a criação de vínculos entre os equipamentos públicos da saúde e da educação (Brasil, 2010a).

O objetivo do PSE é contribuir para a formação integral dos estudantes por meio das referidas ações, visando ao enfrentamento das vulnerabilidades que põem em risco o pleno desenvolvimento de crianças e jovens da rede pública de ensino brasileiro (idem). O programa prevê que, gradativamente, as novas ações de saúde escolar deverão ser introduzidas ao Projeto Político Pedagógico (PPP) das escolas (Brasil, 2008b, 2010b), determinando um novo desenho da política de educação em saúde no Brasil (Brasil, 2008a).

Os gestores do PSE estão ordenados, no âmbito nacional, pela Comissão Intersetorial de Educação e Saúde na Escola (CIESE), designada para o estabelecimento de diretrizes da política de educação e saúde na escola (Brasil, 2008c). Ordenados também pelas equipes do MEC e do MS que compõem o Grupo de Trabalho Intersetorial Federal (GTI-F), que tem como competências garantir a agenda da CIESE; promover a articulação entre as secretarias estaduais e municipais de educação e o SUS; subsidiar o planejamento integrado das ações do PSE nos municípios entre o SUS e o sistema de ensino público, no âmbito da educação básica; subsidiar a formulação das propostas de educação permanente dos profissionais de saúde e da educação básica para implementação das ações do programa; apoiar os gestores estaduais e municipais na articulação, planejamento e implementação das ações do PSE; estabelecer, em parceria com as entidades e associações representativas dos secretários estaduais e municipais de Saúde e de Educação, os instrumentos e os indicadores de avaliação do PSE e definir as prioridades e metas de atendimento do PSE (Brasil, 2011).

Nas esferas municipal/estadual/Distrito Federal, a ordenação acontece por meio do GTI, composto por representantes das secretarias de saúde e educação do município (Brasil, 2010c), além de representantes de outros órgãos e instituições (Brasil, 2010b). O GTI tem por incumbência, entre outras, elaborar o projeto do PSE municipal (Brasil, 2008b), bem como o termo de adesão ao programa (Brasil, 2008b, 2010c).

Por representar uma política intersetorial entre os setores Saúde e Educação, instituída por decreto, a intersetorialidade no PSE representa uma inovação e ao 
mesmo tempo um desafio aos gestores. Assim sendo, o objetivo deste estudo foi analisar a percepção de gestores locais sobre a intersetorialidade na condução do referido programa em municípios selecionados.

\section{MÉTODO}

Trata-se de um estudo avaliativo, descritivo, com uma abordagem qualitativa. Utilizou-se uma amostra intencional, a qual se alicerça, conforme Minayo (2000) e Gil (2009), na escolha de um subgrupo da população (conjunto estabelecido de elementos que detém determinados atributos) que, com base nas informações disponíveis, possa ser considerado representativo do universo a ser estudado, reforçando o aprofundamento da compreensão desse subgrupo. Minayo (2000) observa que a abordagem qualitativa não se apoia no critério numérico para assegurar sua representatividade, e sim no aprofundamento e abrangência da compreensão dos sujeitos da pesquisa. Gil (2009) observa que a amostra intencional exige do pesquisador significativo conhecimento da população e do subgrupo selecionado.

Os critérios de inclusão contemplaram gestores no âmbito municipal/estadual/Distrito Federal do PSE em municípios brasileiros, com representação de um município de cada região do país (Norte, Nordeste, Centro-Oeste, Sudeste e Sul), conforme indicação do MS e/ou MEC e de atores que implementaram o PSE em municípios. Foram incluídos os municípios de Curitiba (Sul), Rio de Janeiro (Sudeste), Brasília (Centro-Oeste), Olinda (Nordeste), e Manaus (Norte). Os respondentes compreenderam um gestor do Setor Saúde e um do Setor Educação de cada município escolhido, totalizando dez respondentes.

Os pesquisadores elegeram como instrumento para a coleta de dados um questionário eletrônico enviado por e-mail para os respondentes. Previamente, o questionário foi validado por gestores municipais do PSE e incluiu questões fechadas e abertas sobre as dimensões da intersetorialidade relativas ao PSE. O roteiro do questionário foi composto de questões norteadoras que possibilitaram o alcance do objetivo proposto. Para tanto, foram preestabelecidas quatro categorias que compreenderam: 1) Gestão do PSE; 2) Desenvolvimento das ações intersetoriais; 3) Monitoramento e avaliação das ações; e 4) Sustentabilidade do PSE.

As questões fechadas do questionário foram submetidas à análise descritiva. Para análise das questões abertas, utilizou-se a técnica da análise de conteúdo proposta por Bardin (2009), que é ordenada em três polos cronológicos. Principiou-se com a pré-análise, na qual foi realizada a "leitura flutuante" representando o primeiro contato com os documentos a serem analisados. Neste estudo, realizou-se a leitura das questões abertas do questionário. Em seguida, fez-se a exploração do material, etapa na qual foi realizada a codificação das categorias preestabelecidas e das subcategorias; para tanto, o referencial teórico e o objetivo proposto foram fundamentais. 
A categoria Gestão do PSE incluiu as subcategorias:

1. Instituição do GTI municipal

2. Coordenação do GTI

3. Conflitos e não alternância na coordenação do GTI

4. Competências do GTI

5. Mecanismos de controle da rotatividade no GTI

6. Equanimidade nas decisões no GTI

7. Estratégias e divergências no GTI

8. Setores representados no GTI

A categoria Desenvolvimento das ações intersetoriais abrangeu as subcategorias:

1. Informações para as ações do PSE

2. Mecanismos que favorecem a participação do jovem/adolescente no PSE

4. Ações do PSE relevantes para o município

5. Importante para a intersetorialidade entre a Saúde e a Educação

6. Facilidades do trabalho intersetorial

7. Dificuldades do trabalho intersetorial

8. Capacitações

9. Setores governamentais que se envolvem com o PSE municipal

10. Setores não governamentais que se envolvem com o PSE municipal

11. Envolvimento de estudantes e familiares no PSE

12. Modelo de gestão do Setor Saúde possibilita a ação intersetorial

13. Modelo de gestão do Setor Educação possibilita a ação intersetorial

14. Modelo de gestão do PSE possibilita a ação intersetorial

15. Inserção das ações do PSE no PPP das escolas

16. Gestão de recursos

A categoria Monitoramento e avaliação das açôes compreendeu a subcategoria:

1. Instrumentos de avaliação/monitoramento do PSE municipal

A categoria Sustentabilidade do PSE abrangeu a subcategoria:

1. Estratégias para a sustentabilidade do PSE como política de Estado

Concluiu-se com a etapa de Tratamento dos resultados, inferência e interpretação. Nessa etapa, os resultados dos dados brutos sofreram tratamento de modo que se tornassem significativos; em seguida os pesquisadores passaram a propor inferências, consentindo a passagem da descrição à interpretação. A técnica da análise de conteúdo foi associada ao programa computacional ATLAS.ti 5.2, que possibilitou o estabelecimento de relações e a criação de representações gráficas dos componentes resultantes dos textos das questões abertas. 
Antes de iniciar a coleta de dados, os pesquisadores solicitaram a autorização de cada instituição em que os respondentes atuavam, bem como o Termo de Consentimento Livre e Esclarecido de cada um deles. Os questionários foram respondidos no período de 15 de julho a 7 de agosto de 2011 .

Esta pesquisa foi aprovada pelo Comitê de Ética em Pesquisa da Pontifícia Universidade Católica do Paraná (Parecer n. 0003889/10, Protocolo n. 5.345).

\section{RESULTADOS E DISCUSSÃO}

\section{PERFIL DOS RESPONDENTES, GESTORES DO PSE DOS SETORES SAÚDE E EDUCAÇÃO DOS MUNICÍPIOS}

Todos os respondentes possuíam curso de graduação. Entre os dez participantes, nove haviam feito curso de pós-graduação (incluindo especialização, mestrado e doutorado). Todos participavam ou já haviam participado do GTI em seu município.

\section{GESTÃO DO PSE}

Em relação aos setores que tomaram a iniciativa de incorporar o PSE ao município, os setores Saúde e Educação, em conjunto, foram resposta para quatro respondentes, somente o Setor Educação para um respondente, somente o Setor Saúde para quatro respondentes. Para um respondente também houve a participação da Secretaria de Assistência Social, juntamente com os setores Saúde e Educação. Observou-se que o Setor Saúde apareceu na resposta de nove respondentes (unicamente ou associado a outros setores). O Setor Educação foi declarado na resposta de seis respondentes (unicamente ou associado a outros setores).

Dessa forma, destacou-se o Setor Saúde na iniciativa de incorporar o PSE aos municípios estudados. Esse evento pode estar relacionado ao fato de as portarias relativas à adesão ao PSE (Brasil, 2008b, 2008d, 2010b, 2010c, 2010d, 2010e) serem emitidas pelo MS, portanto mais próximas ao Setor Saúde e à sua atuação.

Em referência à instituição do GTI municipal, a maioria dos respondentes mencionou a participação das secretarias de saúde e de educação, tanto municipais quanto estaduais. A Secretaria de Assistência Social foi participante, juntamente com as secretarias de saúde e de educação, para dois respondentes. Para um respondente, a instituição do GTI partiu do Setor Saúde. Para um respondente, partiu do Setor Educação. Desse modo, destacaram-se as secretarias municipais e estaduais de saúde e de educação. Isso vai ao encontro do que é estabelecido em portarias do PSE (Brasil, 2008b, 2010b, 2010c), ao definirem que os secretários de Saúde e Educação devem instituir o GTI no âmbito municipal, estadual e Distrito Federal. O GTI deve incluir, obrigatoriamente, representantes das secretarias de saúde e de educação do município (Brasil,2010c), além de representantes de outros órgãos/instituições (Brasil, 2010b).

Em relação aos setores representados no GTI, os setores Saúde e Educação foram consenso entre todos os respondentes, seguidos pela universidade para quatro 
deles. Ainda, cinco respondentes indicaram "outros setores" (podendo indicar mais de um setor). Destes, destacaram-se as organizações não governamentais (ONGs), seguidas pela Secretaria de Assistência Social. Esse fato converge para o conceito de que as ações intersetoriais devem ser concebidas no espaço central de uma ação diferenciada, na qual o ato de planejar se alicerça no compartilhamento de poder e em consonância com interesses, saberes e práticas dos diferentes setores envolvidos (Teixeira; Paim, 2000; Junqueira, 2004).

Destacou-se a Secretaria de Assistência Social na parceria com o PSE, que segundo os respondentes participou em alguns casos na iniciativa de incorporar o PSE ao município, na instituição do GTI municipal e na representação do GTI. Fato que também foi observado em um estudo de Westphal e Mendes (2000), ao inferirem que os setores Saúde, Educação e Ação Social tendem a ser os parceiros mais comuns em ações intersetoriais.

Quanto à coordenação do GTI, para quatro respondentes ela era realizada em conjunto entre os setores Saúde e Educação. Para dois respondentes, a coordenação era conjunta entre os setores Saúde, Educação e Assistência Social. Para dois respondentes não existia uma coordenação, sendo o GTI um colegiado, uma mesa-redonda. Para dois respondentes, o Setor Saúde coordenava o GTI. Assim sendo, oito respondentes indicaram para uma coordenação compartilhada. Essa tendência de compartilhamento de gestão fundamenta o processo intersetorial, salientando-se que nenhuma das portarias do PSE faz referência sobre qual setor deve coordenar o GTI. Silva e Rodrigues (2010) observam que na intersetorialidade está latente a transposição de hierarquias e relações de poder entre setores, instituições e segmentos sociais.

Questionados se havia alternância na coordenação do GTI, seis respondentes indicaram "não", dois não sabiam, e para dois havia alternância. Não foram mencionados conflitos em relação a não alternância na coordenação do GTI, o que representa consenso entre os grupos e uma disposição ao trabalho intersetorial. Ressaltaram haver compartilhamento e coordenação colegiada no GTI, comentando também que não sentiam necessidade de ter uma coordenação. Junqueira (2004) observa que a ação intersetorial deve ser integrada e ocasionar modificações nas práticas e na cultura das instituições gestoras.

As competências atribuídas ao GTI estão descritas em portarias (Brasil,2008b, 2010b, 2010c) e, em relação ao seu cumprimento, observou-se a disposição que se comenta a seguir.

Todos os respondentes afirmaram ter cumprido as competências "Identificação de cada instituição integrante do PSE, quantificação do número de escolas, de alunos de cada escola e as questões prioritárias do perfil desses estudantes" e "Alimentação do Cadastro Secretaria com as informações solicitadas, acompanhamento e monitoramento do preenchimento e a atualização dos Cadastros Escola e Unidade Local Integrada, no endereço eletrônico http://simec.mec.gov.br".

Entre os respondentes, nove asseguraram ter cumprido as competências "Mapeamento da rede do SUS na Estratégia Saúde da Família e da rede de escolas federais, estaduais e municipais, criando territórios de responsabilidade, ou seja, 
estabelecendo espaços comuns para atuação de escolas e equipes de saúde"; "Definição dos responsáveis das áreas de saúde e educação pelo acompanhamento do projeto municipal dentro de cada território de responsabilidade"; "Proposta de funcionamento do GTI, periodicidade de reuniões e integrantes"; "Plano de Ação Local"; "Elaboração do projeto do PSE municipal" e "Elaboração do termo de adesão ao PSE".

No que diz respeito às competências "Realização do diagnóstico situacional que compreenda questões referentes aos determinantes sociais, ao cenário epidemiológico e às modalidades de ensino das escolas que estão no espectro de atuação das equipes Saúde da Família que atuam no PSE"; "Definição das atribuições conjuntas das equipes Saúde da Família e das escolas" "Identificação em campo específico, no Sistema de Cadastro Nacional de Estabelecimentos de Saúde (SCNES), das equipes Saúde da Família que atuam ou atuarão no PSE”, oito respondentes afirmaram tê-las cumprido.

Em relação às competências "Definição do professor responsável pela articulação das ações de prevenção e promoção da saúde na escola" e "Programação das atividades do PSE que deverão ser incluídas no Projeto Político Pedagógico de cada uma das escolas", sete respondentes certificaram tê-las cumprido.

Observa-se que, para cada competência, sete a dez respondentes afirmaram ter efetivado o seu devido cumprimento. Isso demonstra comprometimento dos GTIs, já que o PSE é um programa inovador que requer novas articulações entre os setores. As competências assumidas por sete respondentes estão relacionadas ao ambiente escolar, como "Definição do professor responsável pela articulação das ações de prevenção e promoção da saúde na escola", fato que talvez possa ser explicado pela não apropriação por parte dos profissionais da escola dos preceitos de prevenção e promoção da saúde.

Entre as áreas temáticas de ação do PSE, apresenta-se a proposta de educação permanente e a capacitação de profissionais da saúde e da educação (Brasil, 2008a), a fim de facilitar a comunicação e a compreensão dos profissionais de ambos os setores, de modo que fortaleça vínculos e atenda a expectativas mútuas (Brasil, 2009a). Também foi realizada por sete respondentes a "Programação das atividades do PSE que deverão ser incluídas no Projeto Político Pedagógico de cada uma das escolas".

Um mecanismo essencial para a garantia da institucionalização e sustentabilidade das ações é o estímulo à inserção dos temas da promoção da saúde no PPP da escola. Para tanto se faz necessária uma aproximação entre os profissionais dos setores Saúde e Educação, para a reflexão conjunta e o ajuste conceitual de ambos os setores, objetivando a inclusão das ações na rotina da escola (idem).

Além disso, três respondentes declararam ter assumido também outras competências relacionadas às capacitações das ESFs, dos gestores e dos responsáveis do PSE das escolas; formação de grupos de monitoramento e de comitês locais; organização e execução de mostras e seminários visando à divulgação das atividades do PSE.

Quanto à frequência das reuniões do GTI, seis respondentes realizavam reuniões mensais, dois bimestrais e dois quinzenais. Em relação à rotatividade de representantes nas reuniões, sete responderam que não havia rotatividade, e para três havia rotatividade. Os mecanismos de controle da rotatividade foram relacionados ao controle da presença, comunicação da ausência ao gestor hierarquicamente superior, 
saída do representante e solicitação de outro, bem como à institucionalização do GTI ("portaria conjunta saúde e educação").

Para que o GTI possa cumprir com suas atribuições, presume-se a importância de um grupo coeso e compromissado, já que o enfrentamento dos problemas sociais requer a aproximação de vários olhares, compartilhamento de distintos saberes para a elaboração integrada de estratégias que garantam a qualidade de vida dos indivíduos (Junqueira, 2004).

Houve controvérsia em relação à questão se a tomada de decisões no GTI era realizada de forma equânime, pois, cinco "concordaram" e cinco "discordaram". Tanto os respondentes do Setor Saúde quanto os do Setor Educação destacaram a predominância do Setor Saúde na tomada de decisões. Entretanto, todos os respondentes citaram a comunicação, o diálogo e a busca de consenso como estratégias utilizadas em situação de divergência no GTI. Ressalta-se que os respondentes do Setor Educação também foram a favor da representatividade, por meio de "votação" e "decisão pela maioria".

É fundamental que sejam estabelecidos canais comunicativos que possibilitem a definição de objetivos comuns que permitam o planejamento conjunto das ações intersetoriais (Teixeira; Paim, 2000). Pôde-se notar que esses gestores estavam passando por um processo de aprendizagem.

Mendes, Bógus e Akerman (2004) observam que uma etapa inicial deve representar a capacidade gradativa de adaptação às mudanças, superação de modelos de políticas setorizadas e fragmentadas.

Em relação aos tipos de ferramentas ou instrumentos de comunicação utilizados entre os componentes do GTI, e-mails e telefonemas foram citados por todos os respondentes, seguidos por atas e memoriais de reuniões.

\section{DESENVOLVIMENTO DAS AÇÕES INTERSETORIAIS}

Sobre o que é importante para um trabalho intersetorial entre os setores Saúde e Educação, os respondentes de ambos os setores citaram questões relativas à integralidade, à responsabilidade e ao diálogo (Figura 1). Em relação à integralidade, foram destaques: "processo democrático na tomada de decisões" e "orçamento participativo", mencionados por respondentes do Setor Educação; e "compartilhar dos objetivos, interesses, e recursos”, mencionado por respondentes do Setor Saúde.

Quanto à responsabilidade, destacaram-se o compromisso, o envolvimento e a participação. Os respondentes do Setor Saúde ainda citaram questões relativas ao diálogo, como "ter a capacidade de escuta [...]". As respostas demonstraram que esses atores do PSE traziam consigo os conhecimentos necessários para o êxito de um trabalho intersetorial, pois a intersetorialidade fundamenta-se em ações integradoras de diferentes setores que se devem articular, interagir e se complementarem para o enfrentamento dos problemas (Wimmer; Figueiredo, 2006; Brasil, 2009b). 


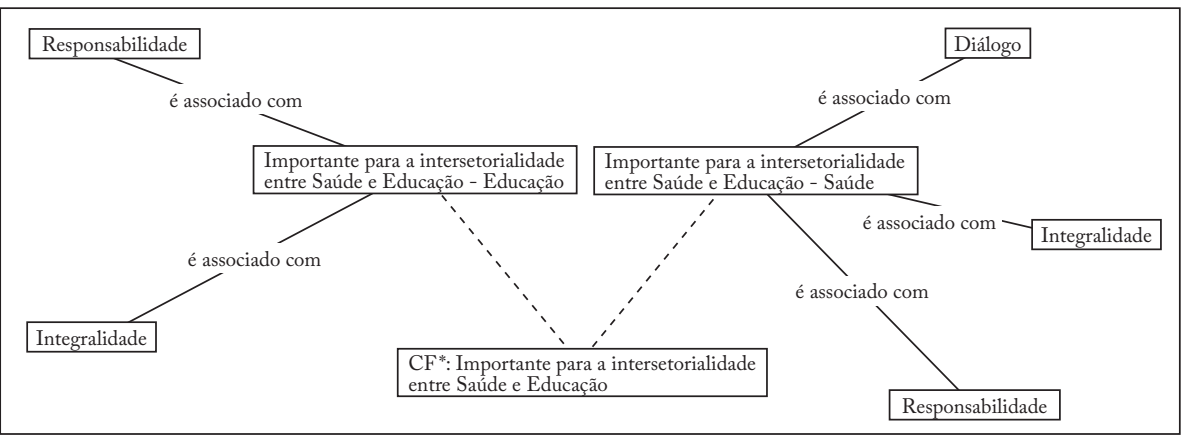

Figura 1 - Teia resultante da análise de indicadores que compõem o que é importante para a intersetorialidade entre os setores Saúde e Educação.

Fonte: pesquisa direta.

Elaboração dos autores.

* O Code Families (CF) é um recurso do ATLAS.ti que agrupa códigos para mostrar as relações entre eles, como em um quadro de codificação.

Em relação ao modelo de gestão de o Setor Saúde possibilitar a ação intersetorial, três respondentes (um do Setor Educação e dois do Setor Saúde) assinalaram "não", os outros sete indicaram "sim". Os que assinalaram "não" ressaltaram a setorização na forma de o Setor Saúde trabalhar e até mesmo "[...] abusar de seu protagonismo nas articulações com outros setores [...]". Os sete que responderam "sim" destacaram a integração do Setor Saúde com outros setores. Destes, um respondente da educação ressaltou que "havia uma tendência à centralização nas tomadas de decisões", embora houvesse esforços para mudanças.

Em relação ao modelo de gestão de o Setor Educação possibilitar a ação intersetorial, três respondentes (um da Educação e dois da Saúde) responderam "não". Para os sete restantes, a resposta foi "sim". Os que responderam "não" revelaram que "[...] a escola é muito fechada em seus processos", "a gestão é setorizada" e "a conversa é difícil pela dificuldade de escuta do outro [...]". Para os sete que responderam "sim", o modelo de gestão é integrado, influente na vida do território.

Em relação ao modelo de gestão de o PSE possibilitar a ação intersetorial, nove responderam "sim" e um respondeu "não". O respondente que assinalou "não" observou que "é preciso [...] que os programas municipais estejam cristalizados em seus propósitos, pois as solicitações do PSE Nacional [...] tendem a ser verticais". Os que responderam "sim" reforçaram a possibilidade de se trabalhar intersetorialmente, já que isso é uma exigência do programa. Destacaram a possibilidade do exercício constante do trabalho colegiado e intersetorial e que o PSE representa um "modelo baseado na democracia, transparência, construção coletiva, cogestão".

O conceito de intersetorialidade pressupõe a disposição de cada setor ao diálogo, ao estabelecimento de vínculos de corresponsabilidade e cogestão (Campos; Barros; Castro, 2004; Junqueira, 2004). Entretanto, vale destacar que os três respondentes que discordaram em relação ao modelo de gestão de o Setor Saúde possibilitar a ação intersetorial ressaltaram questões relativas ao abuso do Setor Saúde em seu protagonismo. Os três respondentes que discordaram em relação ao 
modelo de gestão de o Setor Educação possibilitar a ação intersetorial destacaram que a escola é fechada e o diálogo é difícil.

Aqui cabe uma reflexão: se a escola é fechada à comunicação, esta abre uma lacuna importante para que o outro setor manifeste seu protagonismo nas ações. Nesse sentido, faz-se necessário desenvolver estratégias para estreitar os laços e aproximar olhares entre os setores Saúde e Educação.

Quanto às facilidades do trabalho intersetorial no PSE, estas foram associadas às parcerias ("compartilhamento de responsabilidades"), à avaliação do PSE, à "otimização de recursos financeiros e humanos", à qualidade dos trabalhos e às ações ("maior abrangência e cobertura").

Ao tratarem sobre as dificuldades do trabalho intersetorial no PSE, os respondentes do Setor Educação destacaram a "Centralidade na tomada de decisões", a "Integração em trabalho coletivo", a "Burocracia dos setores", o "Planejamento conjunto das ações". Os respondentes do Setor Saúde destacaram as dificuldades de "Conciliar agenda com diversos atores", "Aceitação de profissionais de outras áreas", "Rotatividade de representantes" e, ainda, que as ações do PSE Nacional são inviáveis localmente (Figura 2).

Para o trabalho intersetorial, deve haver compromisso com um processo de aprendizagem e determinação dos atores envolvidos; ação esta que necessita converter-se na habilidade de dar respostas às necessidades dos cidadãos do território pela melhoria da qualidade de vida (Campos; Barros; Castro, 2004; Junqueira, 2004).

Evidenciou-se que os gestores do PSE estavam num momento de rito de passagem para um novo modelo de gestão que implica mudanças muitas vezes difíceis de serem concebidas de imediato.

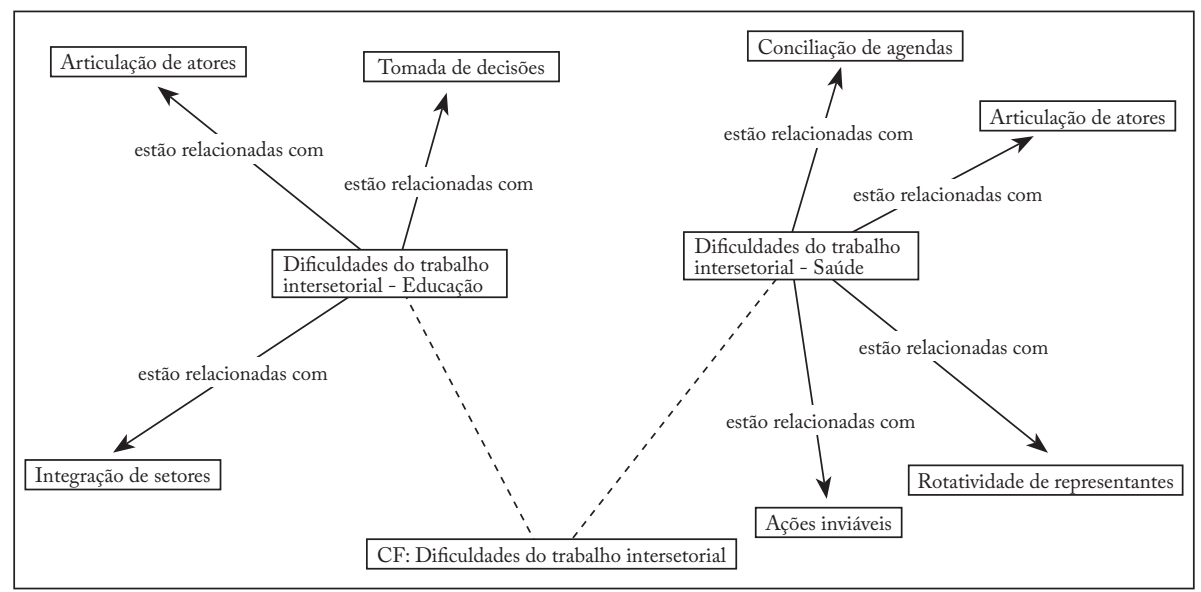

Figura 2 - Teia resultante da análise de indicadores que compõem as dificuldades do trabalho intersetorial no PSE. Fonte: pesquisa direta.

Elaboração dos autores. 
Quando questionados se houve capacitação, no município, para que os profissionais da saúde se apropriassem da linguagem dos profissionais da educação e para que os profissionais da educação se apropriassem da linguagem dos profissionais da saúde, sete responderam "sim", dois "não" e um "não sei".

Também foi questionado se houve capacitação, no município, para que os profissionais da saúde e da educação compreendessem as bases estruturais do PSE. Todos responderam "sim". Entre as áreas temáticas das ações do programa está o processo de capacitação dos gestores e dos profissionais dos setores Educação e Saúde que atuam no PSE (Brasil, 2008a).

As capacitações se fazem importantes na medida em que promovam a aproximação dos profissionais envolvidos no PSE, fomentem a discussão de estratégias para o programa, proporcionem um nivelamento técnico conceitual, de modo que os profissionais envolvidos tenham condições de qualificar a comunicação e o entendimento das bases conceituais do PSE.

Em relação a outros setores governamentais que se envolvem intersetorialmente nas ações desenvolvidas pelo PSE no município, foram citados a Secretaria da Cultura; as universidades federais e estaduais; as secretarias de trabalho e família; os conselhos tutelares, sendo mais citada a Secretaria de Assistência Social. Quanto aos setores não governamentais que se envolvem intersetorialmente nas ações desenvolvidas pelo PSE no município, foram citados o comércio; o MOVPAZ (Cultura da Paz); universidades; Centro de Promoção da Saúde (CEDAPS); Centro de Criação de Imagem Popular (CECIP); Centro Paranaense de Cidadania (CEPAC); Instituto de Defesa dos Direitos Humanos (IDDHEA); conselhos de crianças e adolescentes e ainda pesquisadores das universidades.

Observou-se que os representantes dos GTIs buscavam estabelecer parcerias com outros setores ao desenvolverem suas ações nos territórios. Ao se tratar de um espaço dinâmico, para além do compromisso individual, é necessário mobilizar as organizações presentes na realidade de cada território (Brasil, 2009a). Aqui houve destaque novamente para a Secretaria de Assistência Social, indicando uma adequada escolha para parceria com o PSE.

$\mathrm{Na}$ percepção de quatro respondentes, os estudantes e seus familiares foram envolvidos na definição de prioridades, planejamento e programação de ações locais do PSE. Esse envolvimento foi relatado por meio de oficinas, reuniões, eventos gerais com cobertura jornalística e gravação de vídeos realizados por alunos das escolas. Entretanto, não se observou uma participação efetiva na definição de prioridades, planejamento e programação de ações. Por representar um novo desenho da educação em saúde no país, é fundamental a participação dos estudantes, pais e comunidade na construção e controle social dessa política (Brasil, 2008a).

Houve consenso entre os respondentes do Setor Educação e os do Setor Saúde, quando se trata de que o protagonismo juvenil é um mecanismo que pode favorecer a participação do jovem/adolescente no PSE. Porém, observa-se, mais uma vez, que essa participação deve ser estimulada para que o projeto tenha uma 
atuação efetiva dos estudantes. Os respondentes do Setor Educação também citaram "recursos" para apoio técnico, transporte e apoio às ações.

Também houve consenso entre todos os respondentes sobre a integração do PSE com políticas e programas desenvolvidos por outros setores focados na atenção escolar. Esse fato é relevante, já que o PSE deve articular-se localmente com outros projetos e programas voltados à atenção escolar para reforçar as iniciativas já existentes (Brasil, 2008a).

Em relação se houve levantamento das necessidades do território para as ações do PSE, um respondente "não soube responder" e nove assinalaram "sim". Esse é um fato significativo, pois a intersetorialidade compreende a prática de ações territoriais constituindo-se numa nova abordagem aos problemas sociais (Junqueira, 2000).

Para esses nove respondentes, os participantes do levantamento foram (podendo indicar mais de uma resposta): o GTI, citado por seis; os profissionais da escola, citados por oito; os profissionais das unidades de saúde, citados por oito; a comunidade e estudantes, citados por três. As informações para o levantamento foram pesquisadas nas escolas, unidades de saúde, comunidades, censo escolar, relatório de acompanhamento da saúde, nas bases de dados da Saúde e Educação, nas secretarias de saúde e educação.

Essas informações foram utilizadas para definição de metas, objetivos, priorização de ações; "mapeamento de dados"; "planejamento das ações"; "formação de banco de dados"; "questionários, fóruns e reuniões". As fontes do levantamento foram abrangentes, proporcionando ampla estratégia para a coleta de informações, as quais devem ter sido empregadas de modo que pudessem construir e fortalecer as ações para o PSE local.

Perguntados sobre as ações do PSE que foram relevantes para o município, as respostas foram relacionadas à prevenção de doenças e atenção à saúde ("educação sexual e reprodutiva"; "prevenção de DSTs e gravidez na adolescência"; "ações de saúde bucal"; "controle de peso"; "prevenção do tabagismo"; "implantação do Projeto Olhar Brasil"; "distribuição de óculos"; "levantamento de alterações posturais") e com o envolvimento ("acompanhamento familiar"; "planos de ação local"; "trabalho em equipe"; "valorização da escuta e descentralização das ações"; "envolvimento dos professores"; "fóruns; seminários e encontro locais") e promoção da saúde, caso as ações descritas contemplassem seus princípios e valores, que de acordo com Westphal (2006) incluem a integralidade, a equidade, a participação social, o empoderamento, a autonomia, a sustentabilidade e a intersetorialidade.

Em relação à afirmação: "A maioria das escolas que participa do PSE no seu município desenvolveu propostas para a inserção dos temas da saúde no PPP de forma intersetorial". Sete respondentes "concordaram", dois "discordaram" e um não "soube precisar". As bases estruturais do PSE designam que as ações inovadoras de saúde na escola devem, gradativamente, ser incluídas ao PPP da escola (Brasil, 2008a). 
Questionados se, no seu município, a gestão dos recursos do PSE era feita de forma intersetorial, seis respondentes "concordaram", dois "discordaram" e dois não "souberam precisar". A referida gestão deve ser intersetorial, tendo como responsável o GTI municipal (Brasil, 2011).

\section{MONITORAMENTO E AVALIAÇÃO DAS AÇÕES}

Quanto aos instrumentos utilizados para a avaliação e monitoramento das ações do PSE no município, as respostas foram relativas aos questionários de monitoramento; ao instrumento do MEC e MS; ao instrumento elaborado pelo GTI; ao Sistema Integrado de Monitoramento Execução e Controle do Ministério da Educação (SIMEC); ao banco de dados da Secretaria da Saúde; aos núcleos de monitoramento; às reuniões com as ESFs e escola; e aos relatórios. Esses instrumentos vão além do que está definido em portaria (Brasil, 2010b), que aponta o SIMEC como instrumento de monitoramento.

Para nove respondentes, o PSE vinha promovendo a cidadania e a garantia de direitos humanos nos territórios de atuação. A afinidade entre os setores Saúde e Educação se sobressai no âmbito das políticas públicas por estes serem alicerçados na universalização dos direitos fundamentais dos cidadãos (Silva; Rodrigues, 2010).

\section{SUSTENTABILIDADE DO PSE}

Em referência às estratégias importantes para a sustentabilidade do PSE como política de Estado, as respostas estiveram relacionadas ao fortalecimento da inserção do PSE nos municípios e territórios, na rotina das ESFs e escolas e nas metas do governo. Igualmente ao financiamento com previsão e destinação orçamentária e à autonomia, até mesmo para modificar o desenho inicial do programa se for a necessidade da comunidade local. As respostas também estiveram relacionadas à participação mais efetiva dos gestores e à ampliação das ESFs, equipes do PSE e do Programa Mais Educação.

A sustentabilidade do PSE, para além de um programa de governo em uma política de Estado, implica a superação do modelo biomédico de atenção aos estudantes para uma proposta promotora de saúde, com a participação efetiva dos gestores, profissionais das ESFs e da escola, e comunidade escolar (estudantes, pais, comunidade do entorno), no enfrentamento de suas necessidades específicas, proporcionando o trabalho com capacidades individuais e coletivas existentes.

\section{CONSIDERAÇÕES FINAIS}

Os respondentes deste estudo apresentaram conhecimentos necessários para o trabalho intersetorial. Ficou evidenciado, no entanto, que esses gestores estavam passando por um processo de aprendizagem que incluia capacidade de mudanças e superação do modelo antigo de gestão, fazendo-se necessário um ajuste conceitual 
para fortalecer esse processo, que deve ser contemplado por meio de capacitações contínuas e permanentes para os gestores e profissionais envolvidos no PSE, o que já está previsto nas ações do programa.

\section{REFERÊNCIAS}

Bardin, Laurence. Análise de conteúdo. Lisboa: Edições 70, 2009.

Brasil. Decreto n. 6.286, de 5 de dezembro de 2007. Institui o Programa Saúde na Escola (PSE), e dá outras providências. Diário Oficial da União, Brasília, DF, 5 dez. 2007.p. 2.

. Ministério da Saúde. Ministério da Educação. Orientações sobre o Programa Saúde na Escola para a elaboração dos projetos locais. Brasília, DF: Ministério da Saúde, 2008a. Disponível em: <http://dtr2004.saude.gov.br/dab/docs/geral/orientacoes_pse. pdf>. Acesso em: 16 abr. 2009.

Ministério da Saúde. Portaria n. 1.861, de 4 de setembro de 2008. Estabelece recursos financeiros pela adesão ao PSE para municípios com equipes de Saúde da Família, priorizados a partir do Índice de Desenvolvimento da Educação Básica (IDEB), que aderirem ao Programa Saúde na Escola (PSE). Diário Oficial da União, Brasília, DF, 24 set. 2008b. Seção 1, p. 39.

. Ministério da Educação. Portaria interministerial n. 675, de 4 de junho de 2008. Institui a Comissão Intersetorial de Educação e Saúde na Escola. Diário Ofcicial da União, Brasília, DF, 27 ago. 2008c. Seção1, p. 14.

Ministério da Saúde. Portaria n. 2.931, de 4 de dezembro de 2008. Altera a portaria n. 1.861/GM, de 4 de setembro de 2008, que estabelece recursos financeiros pela adesão ao Programa Saúde na Escola (PSE) e credencia municípios para o recebimento desses recursos. Diário Oficial da União, Brasília, DF, 4 dez. 2008d. Seção 1, p. 46.

. Ministério da Saúde. Secretaria de Atenção à Saúde. Departamento de Atenção Básica. Saúde na escola. Brasília, DF: Ministério da Saúde, 2009a. 96 p. (Série B. Textos Básicos de Saúde. Cadernos de Atenção Básica, n. 24).

Ministério da Saúde. Conselho Nacional das Secretarias Municipais de Saúde. O SUS de A a Z: garantindo saúde nos municípios. 3. ed. Brasília, DF: Ministério da Saúde; 2009b. 480 p. + 1 CD-ROM (Série F. Comunicação e Educação em Saúde).

. Ministério da Educação. Secretaria de Educação Continuada. Alfabetização e diversidade. Programas e açôes. Brasília, DF: Ministério da Educação, 2010a. Disponível em: <http://portal.mec.gov.br/index.php?option=com_content\&view=arti cle\&id=14578\%3 Aprograma-saude-nas-escolas\&catid=194\%3Asecad-educacaocontinuada\&Itemid=817 >. Acesso em: 17 mar. 2010.

Portaria interministerial n. 3.696, de 25 de novembro de 2010. Estabelece critérios para adesão ao Programa Saúde na Escola (PSE) para o ano de 2010 e divulga a lista de municípios aptos para Manifestação de Interesse. Diário Oficial da União, Brasília, DF, n. 226, 26 nov. 2010b. Seção 1, p. 64. 
Ministério da Saúde. Portaria n. 3.146, de 17 de dezembro de 2009. Estabelece recursos financeiros para municípios com equipes de Saúde da Família, que aderirem ao Programa Saúde na Escola (PSE). Diário Oficial da União, Brasília, DF, n. 37, 25 fev. 2010c. Seção 1, p. 32.

Ministério da Saúde. Portaria n. 790, de 12 de abril de 2010. Altera a portaria n. 3.146/GM, de 17 de dezembro de 2009, que estabelece recursos financeiros pela adesão ao Programa Saúde na Escola (PSE). Diário Oficial da União, Brasília, DF, 12 abr. 2010d. Seção 1, p. 35.

Ministério da Saúde. Portaria n. 1.537, de 15 de junho de 2010. Credencia municípios para o recebimento de recursos financeiros pela adesão ao Programa Saúde na Escola (PSE), conforme a portaria n. 3.146/GM, de 17 de dezembro de 2009. Diário Oficial da União, Brasília, DF, 15 jun. 2010e. Seção 1, p. 83.

. Ministério da Saúde. Secretaria de Atenção à Saúde. Departamento de Atenção Básica. Instrutivo PSE. Brasília, DF: Ministério da Saúde;2011. 46 p. (Série C. Projetos, Programas e Relatórios).

Campos, Gastão Wagner; Barros, Regina Benevides de; Castro, Adriana Miranda de. Avaliação de política nacional de promoção da saúde. Ciência E' Saúde Coletiva, Rio de Janeiro: ABRASCO, v. 9, n. 3, p. 745-749, jul./set. 2004.

Gil, Antonio Carlos. Métodos e técnicas de pesquisa social. 6. ed. São Paulo: Atlas, 2009. JunQueIRA, Luciano Prates. Intersetorialidade, transitorialidade e redes sociais na saúde. Revista de Administração Pública, Rio de Janeiro: FGV/EBAPE, v. 34, n. 6, p. 35-45, nov./dez. 2000.

. A gestão intersetorial das políticas sociais e o terceiro setor. Saúde e Sociedade, São Paulo: Associação Paulista de Saúde Pública, v. 13, n. 1, p. 25-36, jan./abr. 2004.

Mendes, Rosilda; Bógus, Cláudia Maria; Akerman, Marco. Agendas urbanas intersetoriais em quatro cidades de São Paulo. Saúde e Sociedade, São Paulo: Associação Paulista de Saúde Pública, v. 13, n.1, p. 47-55, jan./abr. 2004.

Mendonça, Claunara Schilling. [Entrevistas]. Revista Brasileira Saúde da Familia, Brasília, DF, n. 20, p. 6-7, out./dez. 2008.

Minayo, Maria Cecília de Souza. O desafio do conhecimento: pesquisa qualitativa em saúde. 7. ed. São Paulo: Hucitec; Rio de Janeiro: ABRASCO, 2000. 269 p.

Silva, Kenia Lara; Rodrigues, Andreza Trevenzoli. Ações intersetoriais para promoção da saúde na estratégia Saúde da Família: experiências, desafios e possibilidades. Revista Brasileira de Enfermagem, Brasília, DF: Associação Brasileira de Enfermagem, v. 63, n. 5, p. 762-769, set./out. 2010.

Teixeira, Carmen Fontes; Paim, Jairnilso Silva. Planejamento e programação de ações intersetoriais para a promoção da saúde e da qualidade de vida. Revista de Administração Pública, Rio de Janeiro, FGV/EBAPE, v. 34, n. 6, p. 63-80, nov./dez. 2000. 
Westphal, Márcia Faria; Mendes, Rosilda. Cidade saudável: uma experiência de interdisciplinaridade e intersetorialidade. Revista de Administração Pública, Rio de Janeiro: FGV/EBAPE, v. 34, n. 6, p. 47-61, nov./dez. 2000.

Westranal, Márcia Faria. Promoção da saúde e prevenção de doenças. In: Campos, Gastão Wagner de Souza; Minayo, Maria Cecília de Souza; Arerman, Marco; Drumond Júnior, Marcos; Carvalho, Yara Maria de. Tratado de saúde coletiva. São Paulo; Rio de Janeiro: Hucitec/FIOCRUZ, 2006. p. 635-667.

Wimmer, Gert Ferreira; Figueiredo, Gustavo de Oliveira. Ação coletiva para qualidade de vida: autonomia, transdisciplinaridade e intersetorialidade. Ciência E Saúde Coletiva, Rio de Janeiro; ABRASCO, v. 11, n. 1, p. 145-154, jan./mar. 2006.

\section{SOBRE OS AUTORES}

Izabel do Rocio Costa Ferreira é doutora em odontologia pela Pontifícia Universidade Católica do Paraná (PUC-PR). Professora da Universidade Federal do Paraná (UFPR).

E-mail: izabelferreira21@gmail.com

Samuel Jorge Moysés é doutor em epidemiologia e saúde pública pela Universidade de Londres (Inglaterra). Professor da Pontifícia Universidade Católica do Paraná (PUC-PR).

E-mail: s.moyses@pucpr.br

Beatriz Helena Sottile França é doutora em radiologia odontológica pela Universidade Estadual de Campinas (UNICAMP). Professora da Pontifícia Universidade Católica do Paraná (PUC-PR).

E-mail: beatriz.franca@pucpr.br

Max Luiz de Carvalho é mestre em odontologia pela Pontifícia Universidade Católica do Paraná (PUC-PR).

E-mail:maxluizz@gmail.com

Simone Tetu Moysés é doutora em epidemiologia e saúde pública pela Universidade de Londres (Inglaterra). Professora da Pontifícia Universidade Católica do Paraná (PUC-PR).

E-mail: simone.moyses@pucpr.br

Recebido em março de 2012 Aprovado em novembro de 2013 


\section{IZABEL DO ROCIO COSTA FERREIRA, SAMUEL JORGE MOYSÉS, BEATRIZ HELENA SOTTILE FRANÇA, MAX LUIZ DE CARVALHO E SIMONE TETU MOYSÉS}

\section{Percepções de gestores locais sobre a intersetorialidade no Programa Saúde na Escola}

O objetivo deste estudo foi analisar a percepção de gestores locais sobre a intersetorialidade na condução do Programa Saúde na Escola (PSE) em municípios selecionados. Trata-se de um estudo avaliativo, descritivo, com abordagem qualitativa e amostra intencional. O instrumento para coleta de dados foi por meio de questionário eletrônico. Para a avaliação das questões fechadas, realizou-se a análise descritiva dos dados. Para a análise das questões abertas, utilizou-se a técnica da análise de conteúdo proposta por Bardin, associada ao programa computacional ATLAS.ti. Os resultados revelaram que os respondentes demonstram conhecimentos necessários para o trabalho intersetorial, ainda que precisem de ajustes conceituais. Não se observou participação dos estudantes na definição de prioridades, planejamento e programação das ações. Concluiu-se que capacitações são necessárias para aproximação dos profissionais envolvidos no PSE, a fim de qualificar a comunicação e o entendimento das bases conceituais do programa.

Palavras-chave: promoção da saúde; saúde escolar; ação intersetorial; avaliação em saúde.

Local managers' perceptions of intersectoriality in the School Health Program

This study aimed to analyze the coordination of School Health Program (PSE) (Programa Saúde na Escola) and the perception which local managers had of the intersectioriality 
of the program. This is an evaluative and descriptive study with a qualitative approach and an intentional sample. The instrument for data collection was an electronic questionnaire. For the evaluation of closed questions, a descriptive analysis of data was carried out. For the analysis of open questions, the technique of content analysis proposed by Bardin was employed, along with the computer program ATLAS.ti. The results revealed that the respondents had the necessary knowledge for intersectoral work; however, it still needed conceptual adjustments. Furthermore, students did not participate in setting priorities, planning or scheduling actions. Therefore, it was concluded that training is needed to approach the professionals involved in PSE to enhance the communication and understanding of the conceptual foundations of the program.

Keywords: health promotion; school health; intersectoral action; assessment in health.

\section{Percepciones de los gestores locales sobre la intersectorialidad en el Programa Saúde na Escola}

El objetivo del estudio fue analizar las percepciones de los gestores locales de la coordinación del Programa Saúde na Escola (PSE), sobre la intersectorialidad de dicho programa. Es un estudio descriptivo, de evaluación, con enfoque cualitativo y muestra intencional. El instrumento de recopilación de datos fue un cuestionario electrónico. Para la evaluación de preguntas cerradas se llevó a cabo el análisis descriptivo de los datos. Para el análisis de preguntas abiertas, se utiliza la técnica de análisis de contenido propuesto por Bardin, asociado al programa ATLAS.ti. Los resultados mostraron que los encuestados tienen los conocimientos necesarios para el trabajo intersectorial, pero necesitan ajustes conceptuales. No bubo ninguna participación de los estudiantes en la definición de prioridades, planificación y programación de las acciones. Se concluyó que entrenamientos son necesarios para el acercamiento de los profesionales involucrados en el PSE con el fin de calificar la comunicación y la comprensión de los fundamentos conceptuales del programa.

Palabras clave: promoción de la salud; salud escolar; acción intersectorial; evaluación en salud. 